\title{
Comparative study on Exterior RCC Beam Column Joint Subjected to Monotonic Loading
}

\author{
S.V.Chaudhari \\ Department of Structural \\ Engineering V.J.T.I. Matunga, \\ Mumbai
}

\author{
K.A.Mukane \\ Department of Structural \\ Engineering V.J.T.I. Matunga, \\ Mumbai
}

\author{
M.A.Chakrabarti \\ Department of Structural \\ Engineering V.J.T.I. Matunga, \\ Mumbai
}

\begin{abstract}
Computer simulation offers the potential for improved understanding of the local and global mechanisms that determine the response of structures to severe loading. The research presented here focuses on development of a finite element model using ABAQUS software to be used in investigating the behaviour of reinforced concrete exterior beam-column connections. Laboratory investigation of reinforced concrete beam-column connections indicates that component failure may result from inelastic material behaviour of plain concrete and reinforcing steel. Thus, model development includes investigating and characterizing the behaviours of these materials. Concrete damaged plasticity model is used to represent the response of plain concrete. Comparison of computed and observed behaviour of reinforced concrete elements indicates that the model used represents the local response mechanisms that determine global behaviour correctly.
\end{abstract}

The current research helps one to have an improved understanding of finite element modelling of reinforced concrete subassemblies in ABAQUS software. Comparison of load displacement diagram of RCC beam column joint subjected to monotonic loading by using ANSYS and ABAQUS nonlinear modelling is represented. It is observe that the ABAQUS software is giving realistic reinforced concrete load displacement behaviour than ANSYS software.

\section{Keywords}

ABAQUS software, ANSYS software, RCC beam column joint, monotonic loading.

\section{INTRODUCTION}

The structural damage observed for reinforced concrete exterior beam column joint and the results of recent experimental investigations suggest that inadequate structural performance may result from the early development of beam-column connection failure mechanisms. Damage suffered by earthquakes over the years has indicated that many structures were found to have serious structural deficiencies today, such deficient joints have insufficient joint transverse reinforcement and insufficient anchorage of the beam bottom reinforcement. Joints around the perimeter of the building are more susceptible than the interior joints; therefore study of exterior joint's performance would be more important. In the exterior joints, initial cracks proceeded diagonally to ward the column are splice region and extended downward to the bottom column, causing spalling of a large column piece and interfering of the beam top bar. Many researchers have made valuable contributions in understanding the behaviour of concrete and have developed sophisticated methods of analysis. Since 1970, analyses of reinforced concrete structures using finite element method, have witnessed a remarkable advancement. These achievements are well documented and available in various reports and technical papers but still there are many areas in which much remains to be understood and researched. The advancement in computing techniques and the computational capabilities of the high end computers has led to a better study of the behaviour of concrete. However, the complex behaviour of concrete sets some limitations in implementing FEM. The complexity is mainly due to non-linear stress-strain relation of the concrete under multi-axial stress conditions, strain softening and anisotropic stiffness reduction, progressive cracking caused by tensile stresses and strains, bond between concrete and reinforcement, aggregate interlocks and dowel action of reinforcement, time dependent behaviour such as creep and shrinkage. For nonlinear analysis many commercial software's are available, such as ANSYS, ABAQUS, NASTRAN, and ADINA. All these software's are not tailor made applications which can work automatically on just feeding simple input data. An acceptable analysis of any structure as a whole or a part there of, using Finite element software, and its correctness totally depends on the input values, especially the material properties used. However when one is working with concrete a sound technical background is required to use material properties in a proper manner and get the desired results. [1]. Nonlinear finite element analysis is used to study behaviour of beam-column joints in reinforced concrete frame. The analysis results can provide a guidance for experimental studies, which can save research time and cost. The finite element software ABAQUS is capable of simulating complex geometrically nonlinear and materially nonlinear problems.

\section{REVIEW ON BEAM-COLUMN JOINT MODELS}

The strength of beam-column joint plays a very important role in the strength of the structure. A literature survey is carried out to have the information about the monotonic loading applied to the beam-column joint. Vladimir Guilherme Haach et al. (2014) [2] experimentally checked the influence of column axial loads in exterior $\mathrm{R} / \mathrm{C}$ beam-column joints by varying column axial loads. The results showed that the column axial load also introduced stresses in the beam longitudinal reinforcement and it increases the stiffness of the joint. S. S. Patil and S. S. Manekari (2013) [3] analysed a reinforced beam-column joint subjected to monotonic loading by using finite element software ANSYS and they checked the behaviour of joint by varying the stiffness of beam and column. They concluded that the behaviour of corner beam 
column joint is different than that of the exterior beam column joint. The nonlinear finite element analysis of RCC interior beam-column joints using ABAQUS software studied by Huangjuan Zhao et al(2012) [4]. They changed the compressive strength and the volumetric percentage of stirrups in there eight models and compared them with experimental work. They concluded that as the compressive strength increases the joint gets more stiff and with increase in the volumetric percentage of stirrups the ultimate capacity of joint increases. Hamid Sinaei et al. (2012) [5] compared the experimental results with the numerical results calculated by using ABAQUS software for the reinforced concrete beam subjected to flexural loading. They noticed that the finite element nonlinear model for reinforced concrete in ABAQUS software shows nearly same behavior as the experimental behavior.

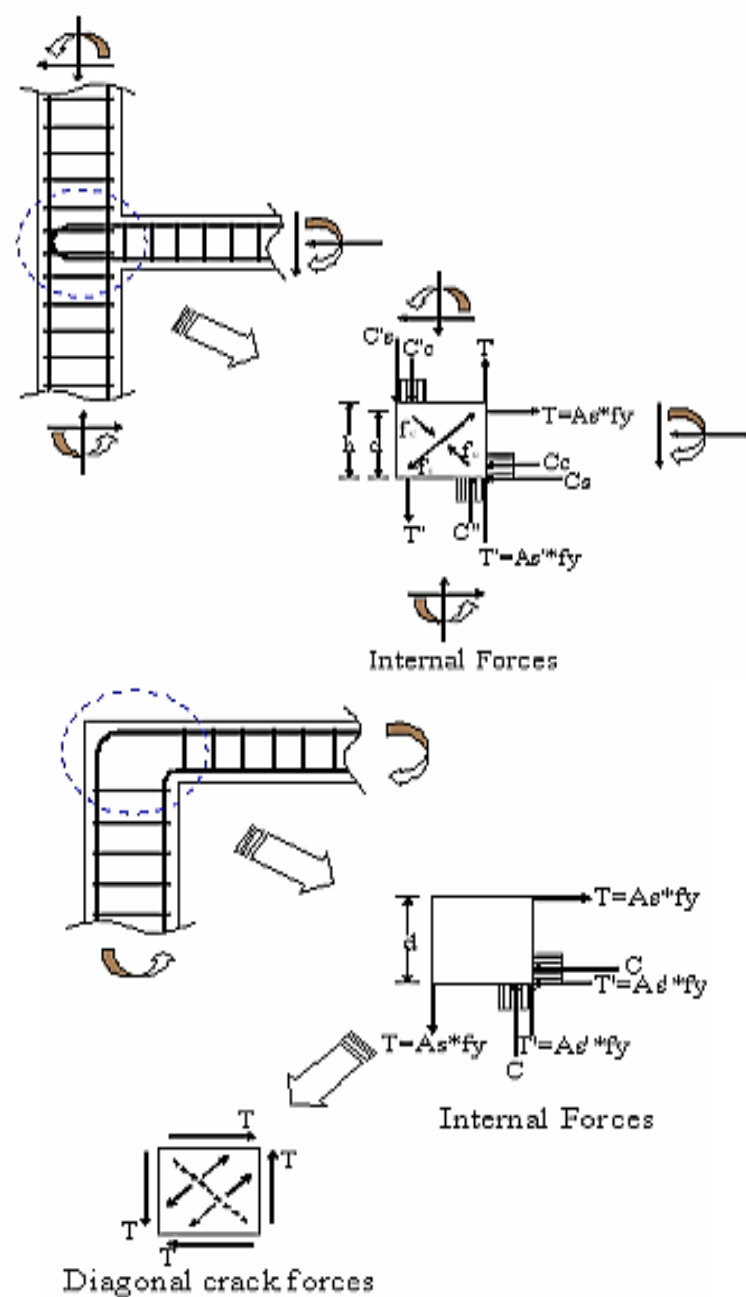

Fig.1 Exterior and corner Beam-Column Joint by S.S. Patil and S.S. Manekari (2013) [3]

Wenqiang Wang and Tieying Li. (2012) [6] simulate the hysteresis curves at three different locations of RC frame and compared them using finite element software ABAQUS. S.V. Chaudhari and M.A. Chakrabarti (2012) [1]were modelled the concrete for nonlinearity and did the convergent study by varying the mesh sizes using finite element code ABAQUS. S.M. Kularni and Y.D. Patil (2012) [7] suggested a new reinforcement pattern for exterior reinforced concrete beamcolumn joint as column crossed inclined reinforcement (CCIR) and compared this with the joint designed and modelled as per IS 13920 by using ANSYS software. P. Kmiecik and M. Kaminski (2011) [8] modelled reinforced concrete structures and composite structures with concrete strength degradation taken into consideration and the degradation parameters explained in detail by using ABAQUS software. Yunus Dere and Fatma Tuba Dede (2011) [9] studied the failure analyses of RC structural frames under monotonic and cyclic loading are carried out by using ANSYS software. Karsten Winkler and Friedhelm Stangenberg (2008) [10] did numerical analysis of punching shear failure of reinforced concrete slabs by using ABAQUS software. Tomasz Jankowiak and Tomasz Odygowski (2005) [11] studied the parameters of concrete damage plasticity constitutive model. M.M. Attard and S. Setunge (1996) [12] gave mathematical model for predicting stress-strain behaviour of bacterial concrete. Hsuan-The Hu.and William C. Schnobrich (1990) [13] did the nonlinear analysis of cracked reinforced concrete. Frank J. Vecchio (1988) [14] studied the nonlinear finite element analysis of reinforced concrete membranes. Eivind and Hognestad (1951) [15] studied combined bending and axial load in reinforced concrete members.

\section{MODELING}

The beam-column joint considered for analysis is studied by S.S. Patil and S.S. Manekari (2013)[2], consists of a cantilever portion and column portion. The column had a cross section of $230 \mathrm{~mm} \times 600 \mathrm{~mm}$ with an overall length of $3000 \mathrm{~mm}$ and the beam had a cross section of $230 \mathrm{mmx} 300$ $\mathrm{mm}$ and the length of the cantilevered portion was $1650 \mathrm{~mm}$. The beam was reinforced using $4 \# 16$ as top and bottom longitudinal bars and \#8@120mm c/c as transverse steel. The column was reinforced with $4 \# 16$ longitudinal bars and \#8 ties spaced $120 \mathrm{~mm}$ [2]. The dimensions and reinforcement details of all of the specimens are identical as shown in Fig.1.

\subsection{Boundary Conditions}

The boundary conditions are set in the model same as in S.S. Patil and S.S. Manekari (2013).

1. Both ends of the column were hinged, the bottom and top of the column is restrained in three degrees of freedom at the $\mathrm{U}_{\mathrm{X}}, \mathrm{U}_{\mathrm{y}}$ and $\mathrm{U}_{\mathrm{Z}}$ directions.

2. Both ends of the column were fixed, The bottom and top of the column is restrained in six degrees of freedom at the $\mathrm{U}_{\mathrm{X}}, \mathrm{U}_{\mathrm{Y}}$ and $\mathrm{U}_{\mathrm{Z}}$ directions and rotations $\mathrm{R}_{\mathrm{x}}, \mathrm{R}_{\mathrm{y}}$ and $\mathrm{R}_{\mathrm{z}}$ directions

\subsection{Material model}

The CDP (Concrete Damaged Plasticity) model used in the ABAQUS software is a modification of the Drucker-Prager strength hypothesis [9]. Parameter $K_{c}$ is interpreted as a ratio of the distances between the hydrostatic axis and respectively the compression meridian and the tension meridian in the deviatoric cross section it's taken as 0.667 . This ratio is always between 0.5 and 1 . Second parameter is eccentricity (plastic potential eccentricity). It is a small positive value which expresses the rate of approach of the plastic potential hyperbola to its asymptote. In other words, it is the length (measured along the hydrostatic axis) of the segment between the vertex of the hyperbola and the intersection of 


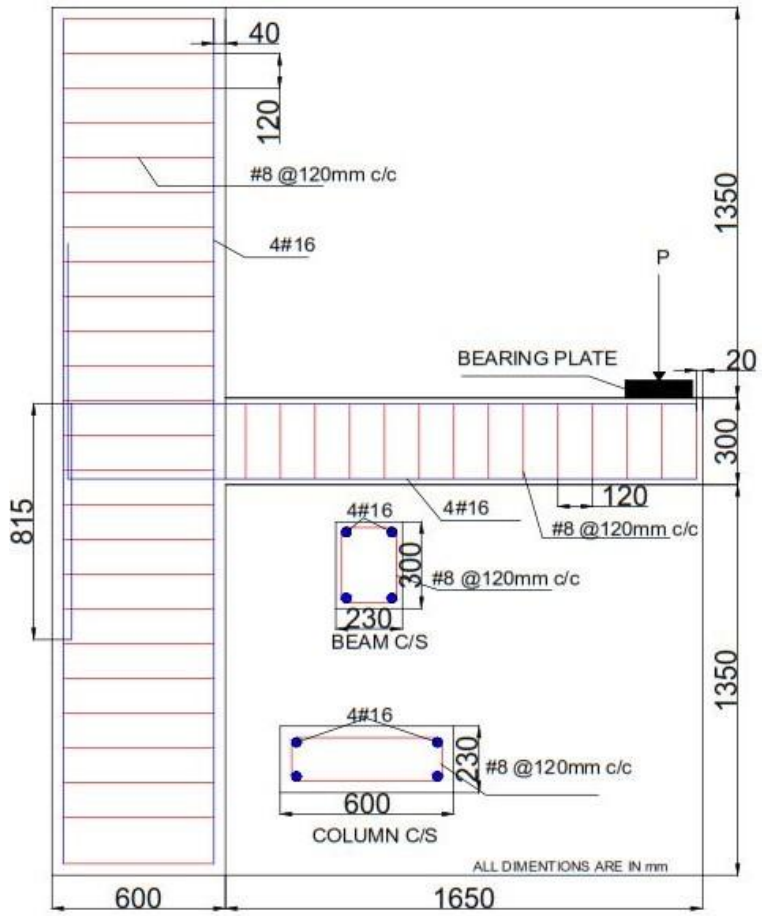

Fig.2 Specimen dimensions and reinforcement details modelled by S.S. Patil and S.S. Manekari (2013) [3]

the asymptotes of this hyperbola (the center of the hyperbola). Parameter eccentricity can be calculated as a ratio of tensile strength to compressive strength. The CDP model recommends to assume $\mathrm{e}=0.1$. Another parameter describing the state of the material is the point in which the concrete undergoes failure under biaxial compression. It is a ratio of the strength in the biaxial state to the strength in the uniaxial state. The ABAQUS user's manual specifies default 1.16. [16]. The last parameter characterizing the performance of concrete under compound stress is dilation angle, i.e. the angle of inclination of the failure surface towards the hydrostatic axis, measured in the meridional plane. Physically, dilation angle $\psi$ is interpreted as a concrete internal friction angle. In simulations usually $\psi=36^{\circ}$ or $\psi=40^{\circ}$ is assumed [8].

The compressive behavior is predicted using following expressions given by Hognestad [15] [1].

$$
\begin{array}{cc}
\frac{\sigma}{\sigma_{\mathrm{cu}}}=2 \frac{\varepsilon}{\varepsilon_{0}}\left(1-\frac{\varepsilon}{2 \varepsilon_{0}}\right) & 0<\varepsilon<\varepsilon_{0} \\
\frac{\sigma}{\sigma_{\mathrm{cu}}}=1-0.15\left(\frac{\varepsilon-\varepsilon_{0}}{\varepsilon_{\mathrm{cu}}-\varepsilon_{0}}\right) & \varepsilon_{0}<\varepsilon<\varepsilon_{\mathrm{cu}}
\end{array}
$$

Where, $\sigma$ is stress at given strain,

$\sigma_{\mathrm{cu}}$ is ultimate compressive stress,

$\varepsilon_{0}$ is strain at $\sigma_{\mathrm{cu}}$

$\varepsilon_{\mathrm{cu}}$ is ultimate strain.

The tension stiffening curve suggested by Hsuan-The $\mathrm{Hu}$ and William C. Schnobrich [13] is used where $\mathrm{f}_{\mathrm{t}}$ and $\varepsilon_{\mathrm{t}}$ are the average tensile stress and strain normal to the crack direction $\theta$ is measured in degrees counter clockwise from the steel direction to the crack direction.

$$
\mathrm{f}_{\mathrm{t}}=\frac{\mathrm{f}_{\mathrm{t}}^{\prime}}{1+\left(1000 * \varepsilon_{\mathrm{t}} *(\theta / 90)^{1.5}\right)}
$$

\subsection{Loads}

Once the reinforcement detailing of the beam and column is known the exterior beam-column joint is modelled in ABAQUS software. Non-linear analysis of exterior joint was carried out with 6 load step. The exterior beam-column joint is modelled and a monotonic loading of $5 \mathrm{kN}$ to $30 \mathrm{kN}$ is applied at the free end tip of the beam till the failure of the beam takes place

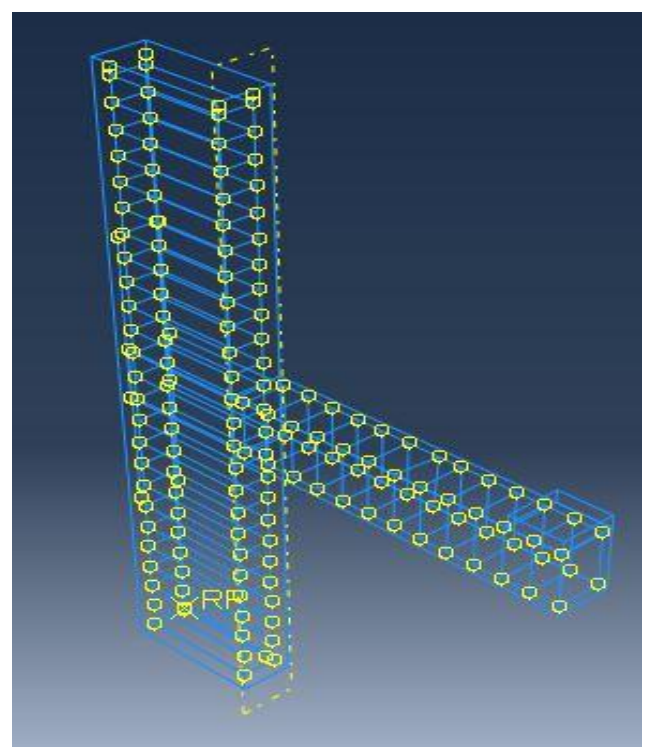

Fig 3 Typical View of ABAQUS Model

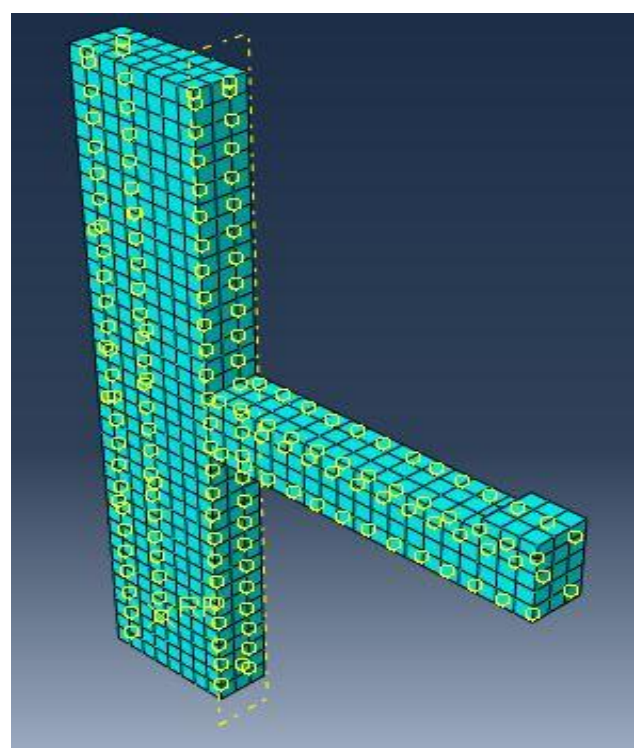

Fig 4 Typical Meshed Specimen

\subsection{The Finite Element Mesh}

The mesh size of $80 \mathrm{~mm}, 60 \mathrm{~mm}$ and $40 \mathrm{~mm}$ are taken for macro-elements in concrete part of the beam and column. In order to obtain accurate results from the FE model, the size of the element meshing is reduces by $20 \mathrm{~mm}$ each time. The 
number of nodes in an element is clearly identified in its name. The 8-node brick element is called C3D8, 2-node truss element is called T3D2.The C3D8 element is used for modelling of concrete and T3D2 element is used for modelling of reinforcement.

\section{VALIDATION OF THE NUMERICAL MODEL}

In order to validate the accuracy and reliability of the numerical model, a numerical analysis of a full scale RC beam-column under monotonic loads was performed using ABAQUS and numerical results are compared with those reported by S.S. Patil and S.S. Manekari (2013)[2]. The typical view of model is as shown in fig 3 and 4 .

\subsection{Review of Modelling using ANSYS}

S.S. Patil and S.S. Manekari (2013)[2] performed monotonic loading on exterior beam-column joints in nonlinear finite element software ANSYS software. They considered exterior and corner beam- column joint to study joint behaviour subjected to monotonic loading. Preparation of FE model was carried out based on results obtained from space frame analysis of a building located in zone-III. The load was applied at the tip of the beam in one direction.

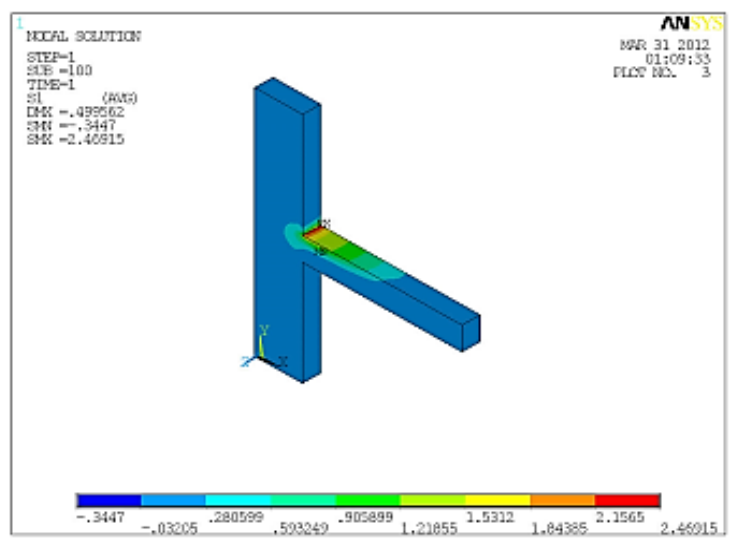

Fig.5 Exterior Joint Modelled in ANSYS

In this, they studied about various parameters for monotonically loaded exterior and corner reinforced concrete beam column joint. The corner as well as exterior beamcolumn joint was analyzed with varying stiffness of beamcolumn joint. The behavior of exterior and corner beam- column joint subjected to monotonic loading was different. Various graphs like load vs displacement, Maximum stress, Stiffness variations i.e. joint ratios of beam-column joints were plotted

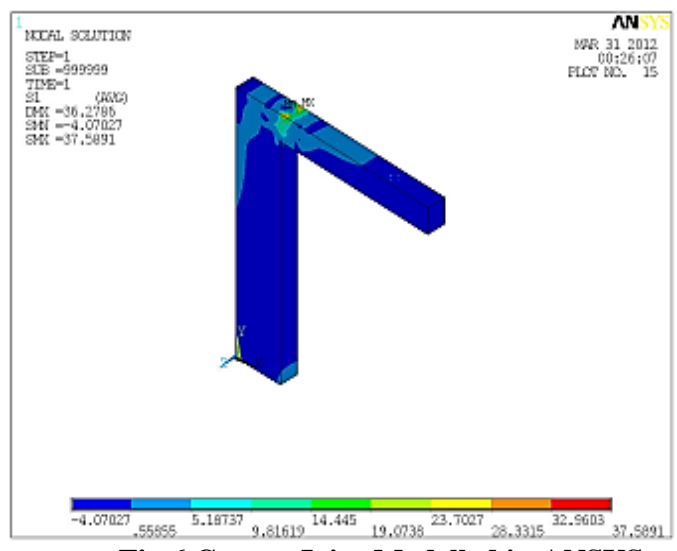

Fig.6 Corner Joint Modelled in ANSYS

\section{FE NUMERICAL RESULTS}

This section presents the output results of the ABAQUS FE model analysis. In the following sections, the loaddisplacement curve comparison between ANSYS and ABAQUS software will be discussed

\subsection{Load-Displacement Curve for Both End Hinged Condition}

The results of finite element analysis using Abaqus for LoadDisplacement for both end hinged condition are as shown in Table-1 and the comparative curves are as shown in Fig.7

\subsection{Load-Displacement Curve for Both End Fixed Condition}

Similarly the FEA results for Load-Displacement for both end fixed condition are given in Table- 2 and the comparative curves are as shown in fig.8.

The graph plotted by using ANSYS is showing that as the load increases the model is getting stiffer and stiffer, whereas in case of ABAQUS model shows the flexible behavior. ABAQUS results show more realistic results for reinforced concrete. As the mesh size of the model reduces the accuracy of the results increases

\section{Table-1 Comparison of ANSYS [2] and ABAQUS Displacement (Hinged Boundary Condition)}

\begin{tabular}{|c|c|c|c|c|c|c|c|}
\hline \multicolumn{8}{|c|}{ MONOTONICLOADING (Hinged condition) } \\
\hline \multirow[t]{2}{*}{$\mathrm{LOAD}(\mathrm{kN})$} & \multirow{2}{*}{$\begin{array}{c}\text { ANSYS } \\
80 \mathrm{~mm}\end{array}$} & \multicolumn{5}{|c|}{ ABAQUS Mesh size } & \multirow[t]{2}{*}{ Difference } \\
\hline & & $30 \mathrm{~mm}$ & $40 \mathrm{~mm}$ & $60 \mathrm{~mm}$ & $80 \mathrm{~mm}$ & $100 \mathrm{~mm}$ & \\
\hline \multicolumn{8}{|c|}{ Displacement in $\mathrm{mm}$} \\
\hline 5 & 0.79 & 0.629 & 0.632 & 0.637 & 0.65 & 0.674 & 0.161 \\
\hline 10 & 1.92 & 1.13 & 1.135 & 1.13 & 1.15 & 1.194 & 0.79 \\
\hline 15 & 2.1 & 1.73 & 1.73 & 1.727 & 1.783 & 1.86 & 0.37 \\
\hline 20 & 2.19 & 2.53 & 2.526 & 2.53 & 2.569 & 2.712 & -0.34 \\
\hline 25 & 2.38 & 3.585 & 3.555 & 3.558 & 3.625 & 3.827 & -1.205 \\
\hline 30 & 2.559 & 4.87 & 4.851 & 4.859 & 4.98 & 5.2 & -2.311 \\
\hline
\end{tabular}




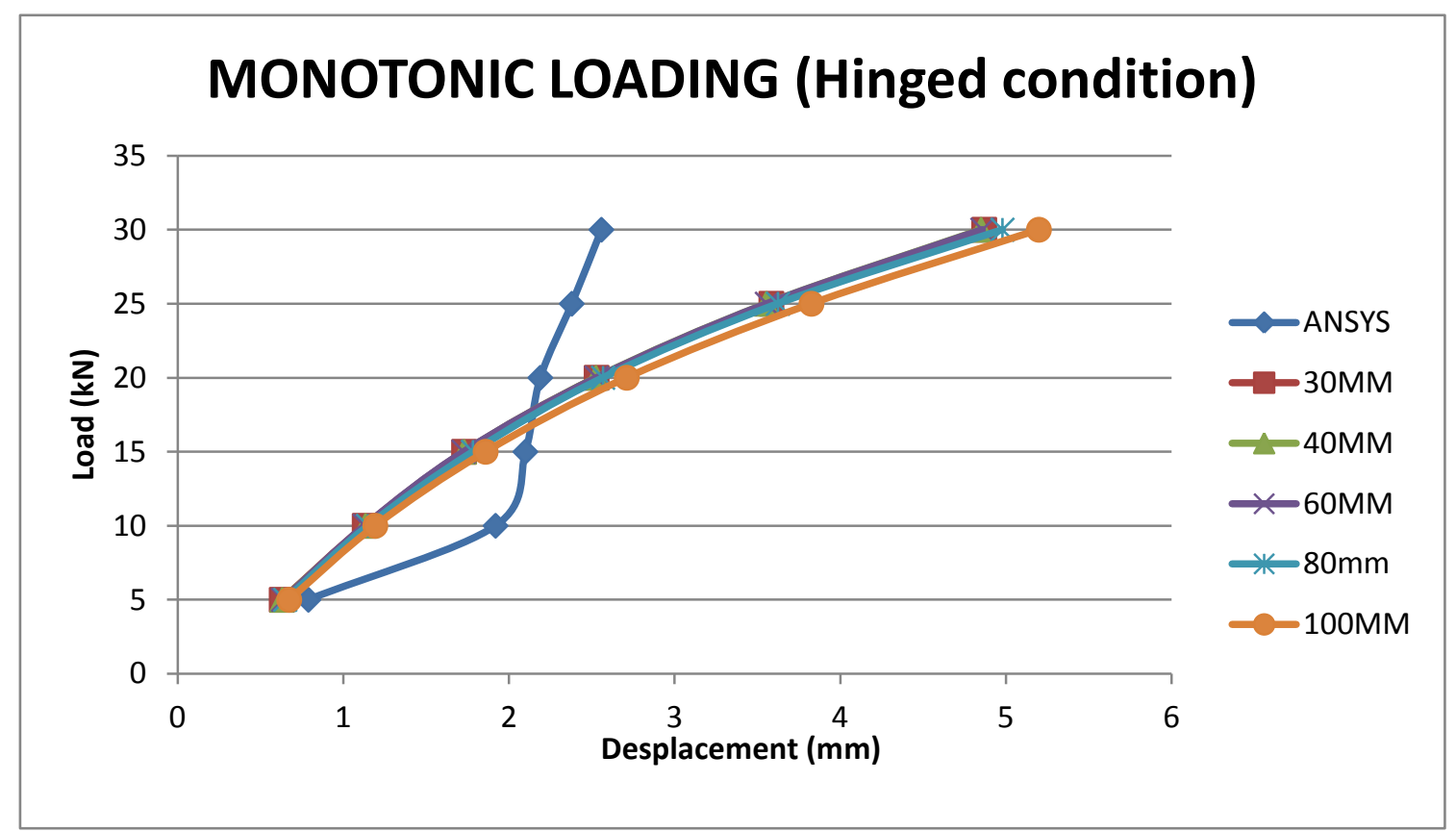

Fig 7 Load vs Displacement for Hinged Condition

Table-2 Comparison of ANSYS [2] and ABAQUS Displacement (Fixed Boundary

Condition)

\begin{tabular}{|c|c|c|c|c|c|c|c|}
\hline \multicolumn{8}{|c|}{ MONOTONIC LOADING (fixed condition) } \\
\hline \multirow[t]{2}{*}{$\mathrm{LOAD}(\mathrm{kN})$} & ANSYS & \multicolumn{5}{|c|}{ ABAQUS Mesh size } & \multirow[t]{2}{*}{ Difference } \\
\hline & $80 \mathrm{~mm}$ & $30 \mathrm{~mm}$ & $40 \mathrm{~mm}$ & $60 \mathrm{~mm}$ & $80 \mathrm{~mm}$ & $100 \mathrm{~mm}$ & \\
\hline \multicolumn{8}{|c|}{ Displacement in $\mathrm{mm}$} \\
\hline 5 & 0.499 & 0.629 & 0.632 & 0.637 & 0.65 & 0.675 & 0.13 \\
\hline 10 & 1.205 & 1.13 & 1.135 & 1.133 & 1.153 & 1.194 & -0.075 \\
\hline 15 & 1.558 & 1.73 & 1.73 & 1.727 & 1.783 & 1.86 & 0.172 \\
\hline 20 & 1.832 & 2.535 & 2.526 & 2.532 & 2.569 & 2.71 & 0.703 \\
\hline 25 & 2.157 & 2.22 & 3.556 & 3.558 & 3.625 & 3.827 & 0.063 \\
\hline 30 & 2.308 & 3.78 & 4.84 & 4.853 & 4.967 & 5.189 & 1.472 \\
\hline
\end{tabular}

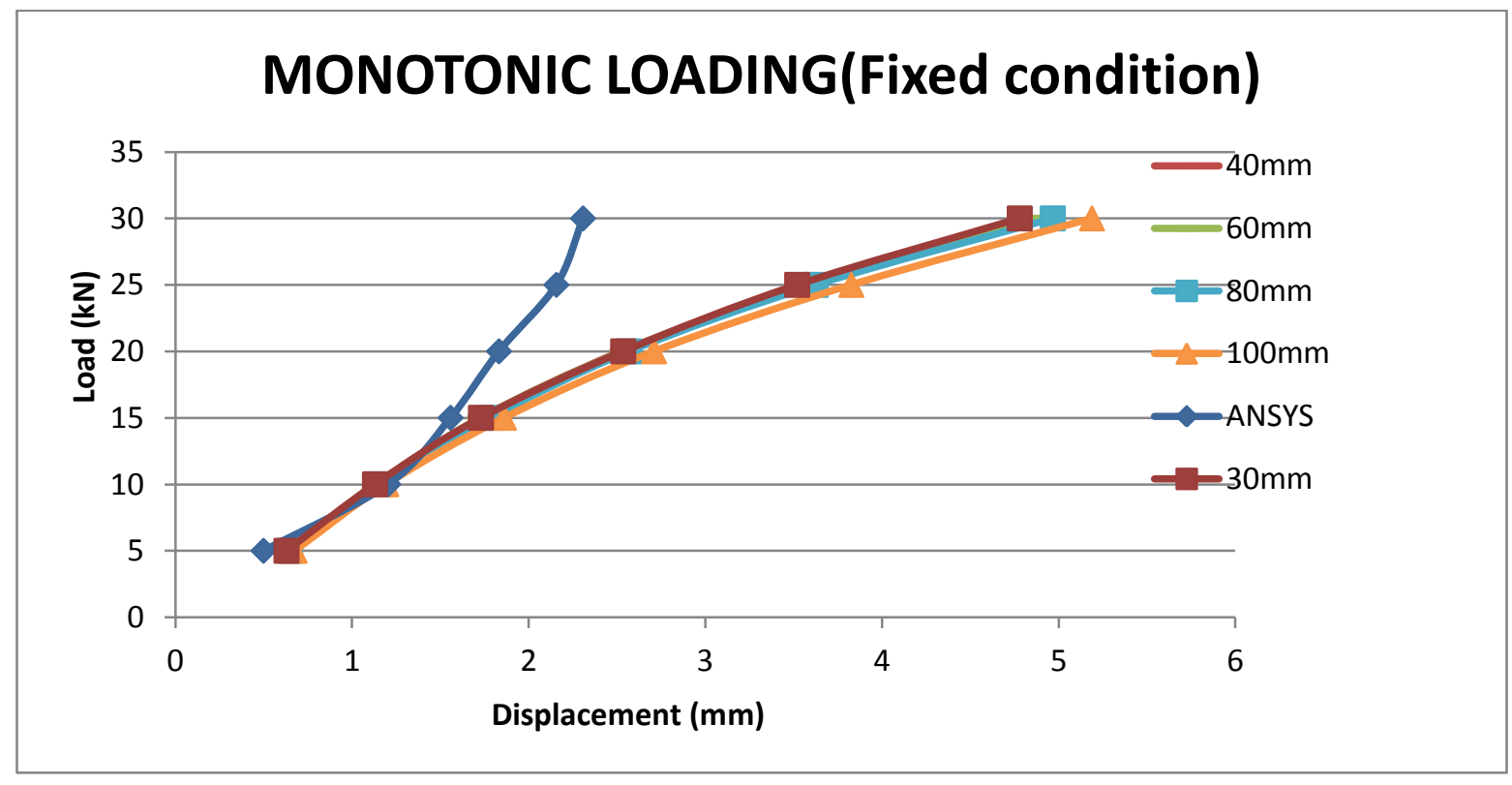

Fig 8 Load vs Displacement for Fixed Condition 


\section{CONCLUSION}

1) The reinforced concrete exterior beam column joint modelled in ABAQUS software with material nonlinearity.

2) From results of both end hinged and fixed condition the load displacement graph drawn. ANSYS results are showing that as the load increases the joint get more stiffened, this graph does not shows or predict the actual reinforced concrete behavior. The ABAQUS results shows the realistic load displacement behavior of the RCC joint

3) As the mesh size decreases the accuracy of the results increases.

4) Still the FE modeling of concrete considering nonlinearity is a topic of research. More research is to be done in this area so that the actual behavior of concrete matches with the FE model of concrete.

\section{ACKNOWLEDGMENTS}

This work is supported by Department of Structural Engineering, Veermata Jijabai Technological Institute, Mumbai - 400019, for providing us ABAQUS 6.12

\section{REFERENCES}

[1] S.V.Chaudhari and M.A.Chakrabarti, "Modeling of concrete for nonlinear analysis Using Finite Element Code ABAQUS," International Journal of Computer Applications, vol. Volume 44- No.7, April 2012.

[2] Ana Lucia Homce De Cresce El Debs and Mounir Khalil El Debs Vladimir Guilherme Haach, "Influence of High Column Axial Loads in Exterior R/C Beam-Column Joints," KSCE Journal of Civil Engineering, pp. 18(2):558-565, 2014.

[3] S. S. Manekari S. S. Patil, "Analysis of Reinforced Beam-Column Joint Subjected to Monotonic Loading," International Journal of Engineering and Innovative Technology (IJEIT), vol. Volume 2, no. Issue 10, April 2013.

[4] Haitao Fan And Zhixin Wang Huangjuan Zhao, "Nonlinear finite element analysis of interior beamcolumn joints in reinforced concrete frame," Applied Mechanics and Materials, vol. Vols. 166-169, pp. 10621066, 2012

[5] Mahdi Shariati, Amir Hosein Abna, Mohammad Aghaei And Ali ShariatI Hamid Sinaei, "Evaluation of reinforced concrete beam behaviour using finite element analysis by ABAQUS," Scientific Research and Essays, vol. Vol. 7(21), pp. 2002-2009, 7 June, 2012.
[6] Tieying Li Wenqiang Wang, "Hysteresis curve simulation of RC frame based on finite element software ABAQUS", 2012.

[7] Y D Patil S M Kularni, "A Novel Reinforcement Pattern for Exterior Reinforced Concrete Beam-Column Joint," Chemical, Civil and Mechanical Engineering Tracks of the 3rd Nirma University International Conference On Engineering (NUiCONE 2012), 2012.

[8] P. Kmiecik and M. Kaminski, "Modelling of Reinforced Concrete Structures and Composite Structures with Concrete Strength Degradation Taken Into Consideration," Archives of Civil and Mechanical Engineering, vol. Vol.-XI, No. 3, 2011.

[9] Yunus Dere. Fatma Tuba Dede, "Nonlinear Finite Element Analysis Of A R/C Frame Under Lateral Loading," Mathematical and Computational Applications, vol. Vol. 16, No. 4, pp. 947-958, 2011.

[10] Karsten Winkler and Friedhelm Stangenberg, "Numerical Analysis of Punching Shear Failure of Reinforced Concrete Slabs," Abaqus Users' Conference, 2008.

[11] Tomasz Odygowski Tomasz Jankowiak, "Identification Of Parameters Of Concrete Damage Plasticity Constitutive Model," Foundation of Civil and Environmental Engineering, vol. 6, 2005.

[12] M.M. Attard and S. Setunge, ACI Materials Journal(Technicaol), vol. Vol. 93, No. 5, pp. 432-441, 1996.

[13] Hsuan-The $\mathrm{Hu}$ and William C. Schnobrich, "Nonlinear Analysis of Cracked reinforced concrete," ACI Structural Journal, vol. title no. 87-S21, March 1990

[14] Frank J. Vecchio, "Nonlinear Finite Element Analysis of Reinforced Concrete Membranes," ACI STRUCTURAL JOURNAL, vol. Title no. 86-S4, 1988.

[15] Hognestad Eivind, "A Study Of Combined Bending And Axial Load In Reinforced Concrete Members," Bulletin Series No. 399, Engineering Experiment Station, University Of Illinois, Urbana, vol. Vol. 49, No. 22, November 1951.

[16] "ABAQUS user's manual 6.12".

[17] Thomas Telford, "CEB-FIP, "Model Code 1990," 1993

[18] "IS-1893-2002 “Criteria For Earthquake Resistant Design Of Structures"".

[19] "IS-13920-1993, “Ductile Detailing of Reinforced Concrete Structures".

[20] "IS 456 : 2000.Plain and Reinforced Concrete - Code of Practice". 